\title{
Ecological consequences of dredging and bottom trawling in the Limfjord, Denmark
}

\author{
Bo Riemann ${ }^{1}$, Erik Hoffmann ${ }^{2}$ \\ ${ }^{1}$ The International Agency for ${ }^{14} \mathrm{C}$ Determination, The Water Quality Institute, Agern Allé 11, DK-2970 Hørsholm, Denmark \\ ${ }^{2}$ Danish Institute for Fisheries and Marine Research, Charlottenlund Castle, DK-2920 Charlottenlund, Denmark
}

\begin{abstract}
During August 1988, effects of mussel dredging and bottom trawling on particulate material, internal nutrient loads, and oxygen balance were examined at 3 shallow locations in Limfjorden, Denmark. Water samples were taken simultaneously from areas exposed to fishing activities and from unused control areas. Sampling was carried out before fishing and 0 (immediately after fishing), 30, and $60 \mathrm{~min}$ after fishing. Sampling and control areas, which were situated close to one another, each covered $160000 \mathrm{~m}^{2}$ and included 9 sampling stations and 3 depths. Immediately after mussel dredging, suspended particulate material increased significantly, but 30 min after dredging these differences had decreased and had returned to the start level after $60 \mathrm{~min}$. The effect per dredged $\mathrm{m}^{2}\left(1850 \mathrm{~m}^{2}\right)$ extrapolated to the total area $\left(160000 \mathrm{~m}^{2}\right)$ was $1470 \mathrm{~g}$ suspended particulate material per $\mathrm{m}^{2}$ dredged, corresponding to an increase of $1361 \%$ on the average suspended particulate material in the water column before dredging. Similar values for eel trawling from 2 different stations gave 960 and $1000 \%$, respectively. Oxygen decreased significantly after mussel dredging and average ammonia content increased, but large horizontal variations in the ammonia content prevented detailed interpretation of these increases. Changes in other nutrients were small. Changes in particulate matter and nutrients were also observed at 2 stations on a day with high $\left(15 \mathrm{~m} \mathrm{~s}^{-1}\right)$ followed by a day with low wind velocity $\left(3 \mathrm{~m} \mathrm{~s}^{-1}\right)$. Particulate matter and total phosphorus were markedly higher on the windy day. A significant proportion of dredging and trawling in the Limfjord takes place during summer, when wind speeds are mostly low, nutrients are low, and oxygen consumption and temperatures are high. During these periods, trawling and particularly dredging reduce the water quality by increasing internal nutrient loads, oxygen consumption, and possibly phytoplankton primary production. An extended evaluation of the ecological role of dredging and trawling requires an estimate of intensity of, and more information on the role of, natural wind-stress.
\end{abstract}

\section{INTRODUCTION}

Bottom trawling and dredging are old industries in many European countries. Much of the gear is designed for shrimps, flatfish, cod, scallops, and blue mussels, and sizes and weights vary from country to country. It is generally believed that the trawl fleet in Europe has expanded during the past 25 yr (ICES 1988) and that the sizes of vessels and the size and weight of the fishing gear used have also increased (ICES 1988).

In Denmark, there are less than 3000 fishing vessels, and the majority are between 20 and 250 GRT (Gross Registered Tonnage), powered by engines of between 200 and $1200 \mathrm{hp}$ (ICES 1988). The total extent of the sea bottom area in Denmark trawled per year is not known, although for the Limfjord area it was calculated that the number of trawl hours per $\mathrm{m}^{2}$ per year corresponded to a total area trawled of $3000 \mathrm{~km}^{2}$, roughly twice the area of the Limfjord (Nielsen 1985). Most of the trawling is for eel. Comparable calculations have been carried out on the basis of data from the Dutch beam trawl fleet, and Rauck (1985) suggested that several areas were trawled 3 to 5 times a year.

Trawling and dredging can be expected to cause a number of direct and indirect changes in the ecosystem. Direct changes in the fish populations and in the benthos can occur (De Groot 1984), and the water column receives organic and inorganic nutrients that may cause significant changes in the nutrient level and in the oxygen budget. Finally, phytoplankton primary production may increase, if it is controlled by nutrients.

The effects of bottom trawling and dredging include direct scraping and the pressure of the gear on the seabed. The magnitude of effect depends on the depth of penetration of the gear into the sediment, the frequency with which the area is fished, and the structure 
of the sediment (De Groot 1984, Redant 1987). The consequences of trawling include changes in the fish stock, and changes in mortality, recruitment/settlement, diversity, and production of benthos (Graham 1955, De Groot 1984, Redant 1987). In addition, resuspension of particles, toxic substances, and nutrients are suspected to affect the oxygen budget and nutrient levels. Unfortunately, the effects of trawling on the nutrient balance and oxygen consumption are poorly understood.

The objective of this study was to examine effects of mussel dredging and eel trawling in the Limfjord. Particular attention was paid to (1) short-term effects of dredging and trawling on sediment resuspended into the water column, (2) changes in the internal loadings of phosphorus and nitrogen, and (3) changes in the oxygen level in the water column. These effects were examined by comparing results obtained from measurement in an area fished by research cutters with results obtained simultaneously from a nearby unfished reference area. Finally, the results of dredging and trawling on the loadings of suspended particulate material and nutrients were compared with natural resuspension from 2 stations in the Limfjord.

\section{MATERIALS AND METHODS}

The Limfjord is a shallow, eutrophic, $150 \mathrm{~km}$ long sound connecting the North Sea with the Kattegat (Fig. 1). Mean depth is about $7 \mathrm{~m}$, maximum depth $15 \mathrm{~m}$, and salinity ranges from 24 to $28 \%$. Summer temperatures range from 16 to $22^{\circ} \mathrm{C}$ and periods with oxygen depletion frequently occur. Phytoplankton primary production is apparently nitrogen-limited during summer. The fishing consists mainly of a trawl fishery for eel (ca $2000 \mathrm{t} \mathrm{yr}^{-1}$ ) and dredging for blue mussels (ca $50000 \mathrm{t} \mathrm{yr}^{-1}$ ).

The sampling programme was carried out on 18 and 19 August 1988 at 3 locations (Fig. 1). On 18 August, starting at 10:30 h, effects of eel trawling were studied at the Island of Fur $\left(56^{\circ} 49^{\prime} 3^{\prime \prime} \mathrm{N}, 8^{\circ} 54^{\prime} 1^{\prime \prime} \mathrm{E}\right)$. Water depth was $7.5 \mathrm{~m}$ and wind speed ca $4 \mathrm{~m} \mathrm{~s}^{-1} \mathrm{SW}$. The current was SW and about $1 \mathrm{~m} \mathrm{~s}^{-1}$ at the surface.

On 18 August, starting at 13:00 h, samples were taken from Thisted Broad $\left(56^{\circ} 55^{\prime} 6^{\prime \prime} \mathrm{N}, 8^{\circ} 43^{\prime} 0^{\prime \prime} \mathrm{E}\right)$. Effects of eel trawling were again examined. Water depth was about $11 \mathrm{~m}$, and wind and current were approximately the same as noted for the morning sampling.

On 19 August, starting at 10:00 h, effects of mussel dredging were examined at Livø $\left(56^{\circ} 50^{\prime} 0^{\prime \prime} \mathrm{N}\right.$, $\left.9^{\circ} 08^{\prime} 5^{\prime \prime} \mathrm{E}\right)$. Water depth was about $9 \mathrm{~m}$. Wind speed was 4 to $6 \mathrm{~m} \mathrm{~s}^{-1} \mathrm{SE}$ in the beginning, increasing to 8 to $10 \mathrm{~m} \mathrm{~s}^{-1}$ at the end of the sampling period.

At each of the 3 locations, fishing and control areas were selected based on depth, bottom conditions and distance from shore. The control area was situted a few hundred meters from the sampling area, sufficient to avoid any contamination from the fishing activities. A grid of 9 buoys constituted the fishing area and a further 9 the control area without fishing (Fig. 2). The buoys were $200 \mathrm{~m}$ apart and the areas of the fishing and control squares were thus $400 \times 400=160000 \mathrm{~m}^{2}$. Water samples were taken at 4 different times from 3 depths in the water column at each of the 18 buoys (Table 1); before fishing, immediately after fishing ( 0 $\mathrm{min})$, and 30 and $60 \mathrm{~min}$ after fishing. At each sampling, a boat was driven from buoy to buoy in the
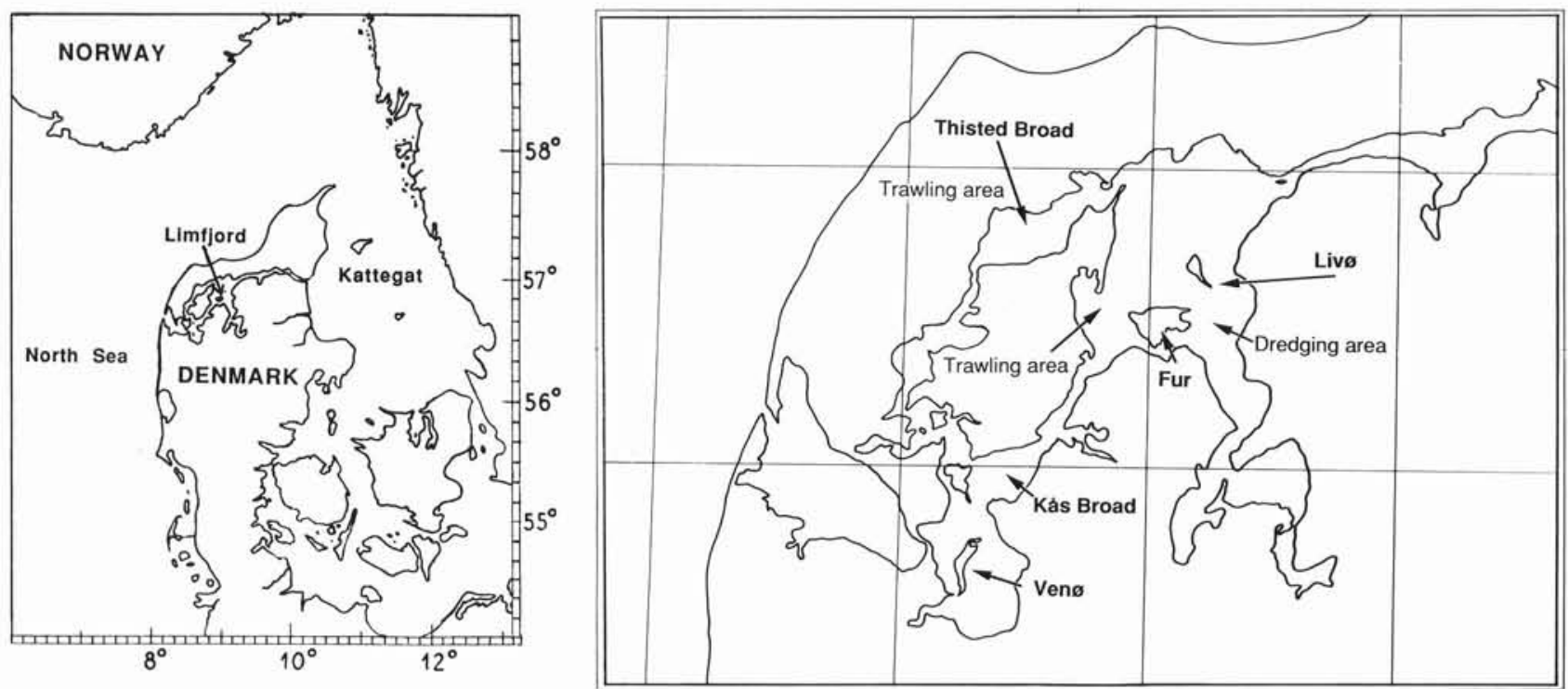

Fig. 1. Denmark and the sampling area in the Limfjord 


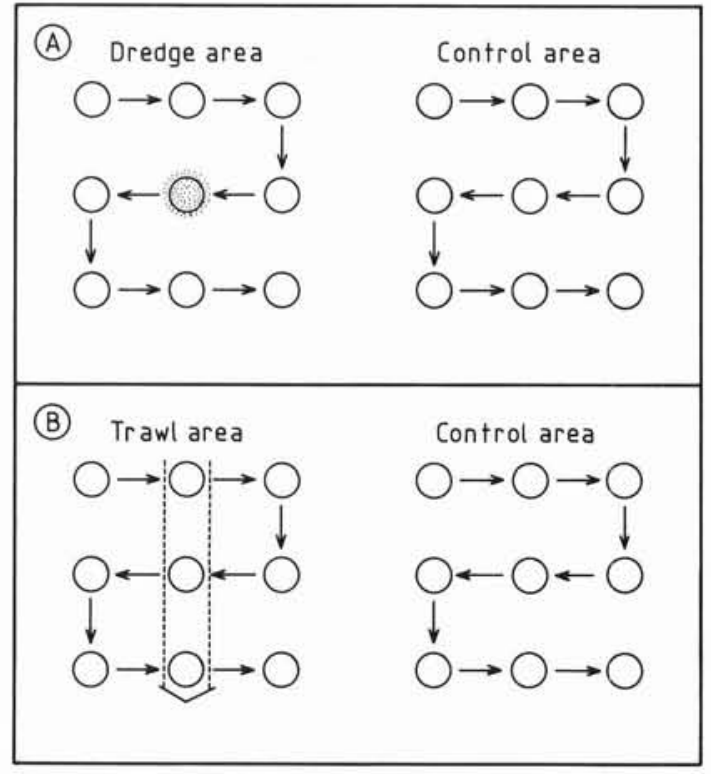

Fig. 2. Diagram of sampling and control areas from (A) the dredging location (Livø) and (B) the trawling locations (Fur and Thisted Broad). Each area included 9 sampling stations. Arrows indicate order of sampling. Large arrow in (B) indicates the trawling direction. Shaded area in (A) indicates dredging area. Distance between sampling stations was $200 \mathrm{~m}$

Table 1. Maximum depth and sampling depths at the 3 locations in the Limfjord

\begin{tabular}{|lcc|}
\hline Location & $\begin{array}{c}\text { Maximum depth } \\
(\mathrm{m})\end{array}$ & $\begin{array}{c}\text { Sampling depths } \\
(\mathrm{m})\end{array}$ \\
\hline Fur & 7.5 & $2-5-6.5$ \\
Thisted & 11.0 & $2-9-10.5$ \\
Livø South & 9.0 & $2-7.5-9$ \\
\hline
\end{tabular}

fishing area, and samples taken at each of the 9 buoys. A second boat (synchronized with the first via radio communication) was used to sample at the 9 buoys in the control area. The sampling succession of the buoys is indicated in Fig. 2. Sampling was completed in $22 \min$ ( $\mathrm{SD} 4 \mathrm{~min}, \mathrm{n}=24$ periods). Dredging lasted $15 \mathrm{~min}$ after which sampling started, the last buoy being sampled $22 \mathrm{~min}$ after the first. Trawling through the sampling area took about $15 \mathrm{~min}$. Sampling was initiated as soon as the trawl passed the first buoy; thus some of the $0 \mathrm{~min}$ samples were in fact taken $7 \mathrm{~min}$ after trawling. No corrections were made for these time differences. The consequence is that the measured effects, particularly with respect to dredging, represent minimum effects since some of the resuspended material was probably moved out of the sampling area by currents before sampling took place.

Mussel dredging was carried out using a dredge of about $2 \mathrm{~m}$ width and weight about $100 \mathrm{~kg}$. Dredging was carried out for $15 \mathrm{~min}$ in a circular manner in the middle of the area (Fig. 2). Towing speed was 2.0 to $2.1 \mathrm{kn}$ and the dredged area was $1850 \mathrm{~m}^{2}$. Trawling was performed using a small-meshed commercial eel trawl (Fig. 3). Towing speed was 2.2 to $2.4 \mathrm{kn}$ and

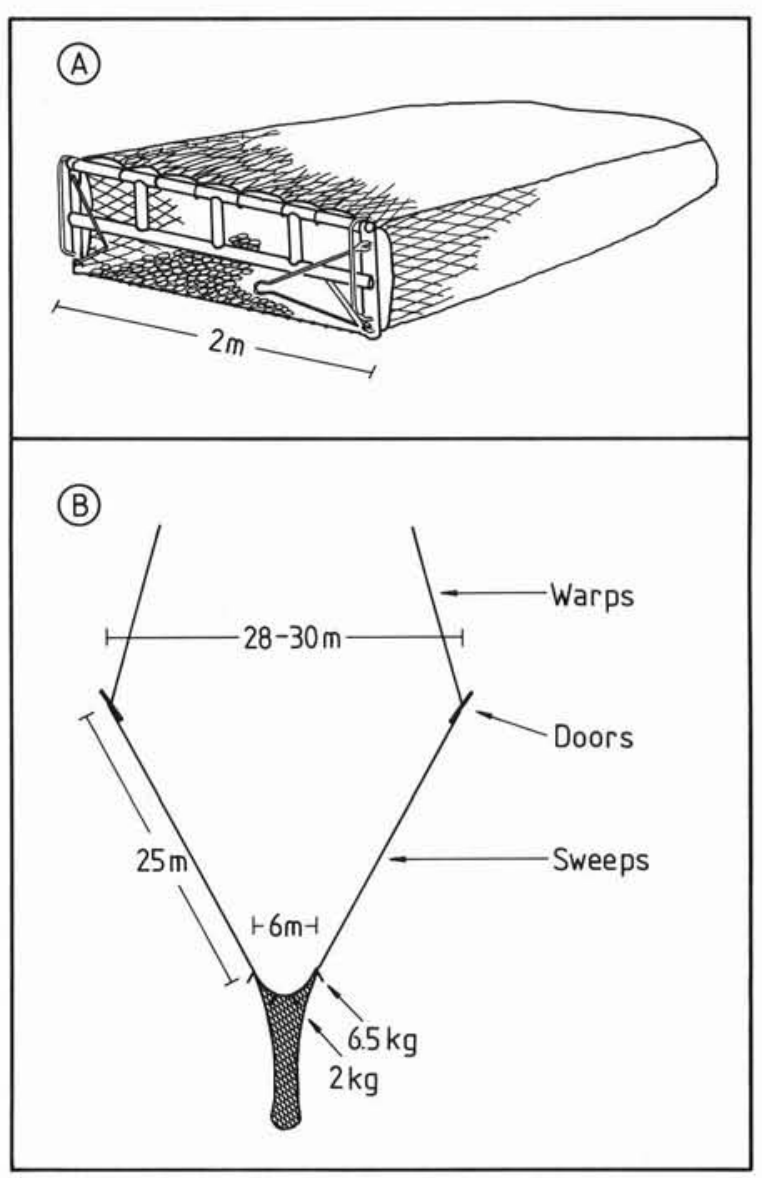

Fig. 3. (A) Mussel dredge; (B) eel trawl

trawling was carried out in the middle of the trawling area (Fig. 2). It was assumed that only the doors, the weights on the ground rope and the central bag resuspended the sediment. Consequently, the area affected by the eel trawl was $6 \times 400=2400 \mathrm{~m}^{2}$.

A 31 plastic water sampler was used, and oxygen was measured at each sampling depth by electrodes calibrated with Winkler titrations before use. Temperature was also recorded. Ammonia was measured using the method described by Solórzano (1969), with the following modifications. Unfiltered samples were used, and reagents added immediately after sampling to avoid changes in the ammonia concentration caused by storage (Riemann \& Schierup 1978). Results from preliminary experiments gave the same ammonia concentrations in filtered (Whatman GF/C) and unfiltered samples. Nitrate and phosphate were measured 
according to Crosby (1967) and Murphy \& Riley (1962), respectively. Silicate was measured according to Mullin \& Riley (1966). Total phosphorus and total nitrogen were measured according to Koroleff (1968) and Jackson (1958), respectively. Suspended particulate matter was determined by filtering 11 samples through GF/C filters (Whatman) of $47 \mathrm{~mm}$. The filters were dried at $105^{\circ} \mathrm{C}$ for $2 \mathrm{~h}$, and weighed. At each of the 3 stations, the coefficients of variation (SD \% of mean), for 10 replicate samples taken from a depth of $2 \mathrm{~m}$, were $<5 \%$ for suspended particulate matter, 2 to $6 \%$ for nitrate and phosphate, 0 to $9 \%$ for ammonia and 0 to $5 \%$ for silicate.

The effects of dredging and trawling were calculated as the average levels of e.g. suspended particulate material found in the sampling area and in the control area before fishing, immediately after fishing $(0 \mathrm{~min})$, and 30 and $60 \mathrm{~min}$ after fishing. These average levels were calculated from the mean value of each vertical profile assuming random distribution of sampling stations. The effects of fishing per $\mathrm{m}^{2}$ actually fished were estimated by recalculation, based on the difference before and after fishing at each sampling station. The average difference for the area as a whole was divided by the fished bottom area (1850 or $\left.2400 \mathrm{~m}^{2}\right)$ and multiplied by the sampling area $\left(160000 \mathrm{~m}^{2}\right)$ to give an extrapolation to the values to be expected if the whole area was fished.

Effects of wind on the transparency of the water and on the concentrations of nitrogen and phosphorus were examined from 2 stations on 7 and 8 February 1989: Kås Broad ( $\left.56^{\circ} 39^{\prime} 40^{\prime \prime} \mathrm{N}, 8^{\circ} 42^{\prime} 38^{\prime \prime} \mathrm{E}\right)$ and Venø Bugt $\left(56^{\circ} 31^{\prime} 39^{\prime \prime} \mathrm{N}, 8^{\circ} 40^{\prime} 46^{\prime \prime} \mathrm{E}\right)$. This time of the year was chosen because it was easier to find periods with high wind speeds. Water samples were taken from $0.2 \mathrm{~m}$ depth on a day with strong winds ( 7 Feb: $15 \mathrm{~m} \mathrm{~s}^{-1}$ ) and on the following day with gentle winds ( $8 \mathrm{Feb}: 3 \mathrm{~m} \mathrm{~s}^{-1}$ ). Transparency was measured using a Secchi disk.

\section{RESULTS}

\section{Effects of mussel dredges}

Measured levels of suspended particulate material, inorganic nutrients, and oxygen are presented for the dredged and control area before dredging, immediately after dredging $(0 \mathrm{~min})$, and 30 and $60 \mathrm{~min}$ after dredging in Fig. 4. Before dredging, only minor horizontal differences were found in the suspended particulate material in the dredged and control areas. Immediately after dredging, the suspended particulate material at $9 \mathrm{~m}$ depth (just above the bottom) increased at several of the buoys and the horizontal variability also increased (data not shown). Thirty minutes after
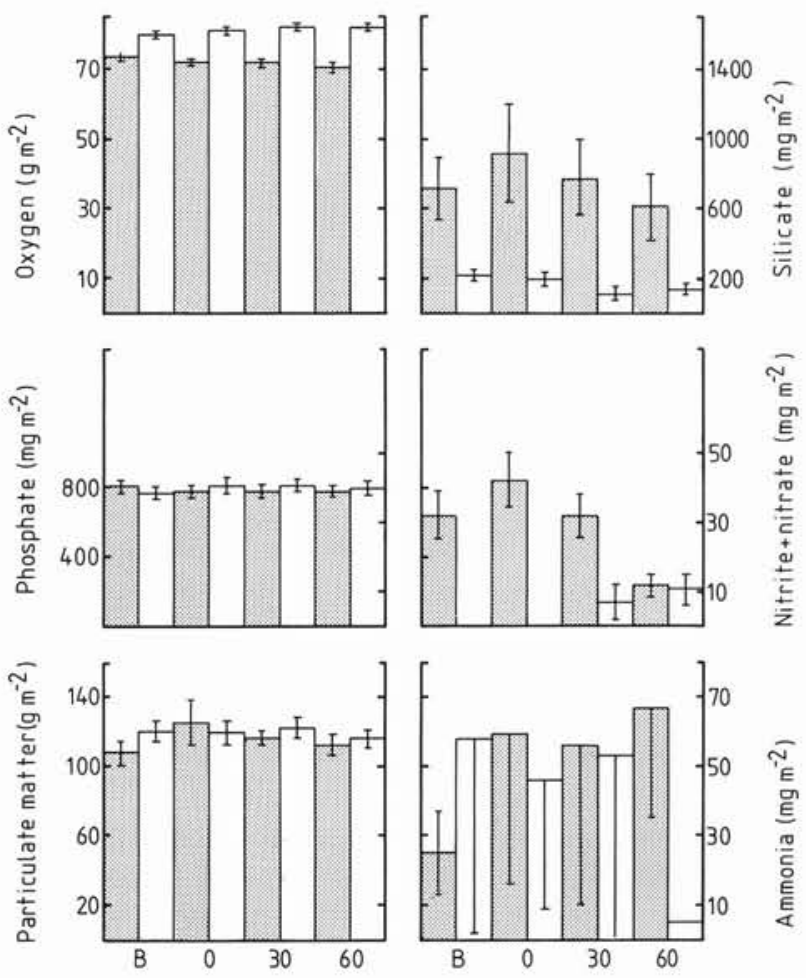

Fig. 4. Depth- and area-integrated values of oxygen, silicate, phosphate, nitrate + nitrite, particulate material, and ammonia at Livø before mussel dredging and 0 (immediately after dredging), 30, and $60 \mathrm{~min}$ after dredging in the sampling area (shaded columns) and in the control area (open) columns). Bars represent SD (standard deviation), $\mathrm{n}=9$ vertical profiles

dredging, these differences decreased and $60 \mathrm{~min}$ after the measurements were back to the start level. Calculated on a $\mathrm{m}^{2}$ basis (Fig. 4), the average suspended particulate material increased significantly (t-test, $\mathrm{p}<0.002$ ) immediately after dredging. In contrast, the suspended particulate material in the control area remained constant, decreasing slightly $60 \mathrm{~min}$ after dredging.

At Livø, the average dry weight increased from 108 to $125 \mathrm{~g} \mathrm{~m}^{-2}$ immediately after dredging. In the control area, corresponding values were 120 and $119 \mathrm{~g} \mathrm{~m}^{-2}$. Assuming that the changes in the dredged area were exclusively caused by dredging, the net increase was $125-108=17 \mathrm{~g}$ dry wt $\mathrm{m}^{-2}$ corresponding to $16 \%$ of the suspended particulate material in the water column before dredging. However, only $1850 \mathrm{~m}^{2}$ of the area was dredged. The effect per $\mathrm{m}^{2}$ dredged extrapolated to the total area $\left(160000 \mathrm{~m}^{2}\right)$ was $(17 \mathrm{~g}$ dry wt/1850) $\times$ $160000=1470 \mathrm{~g}$ dry wt per $\mathrm{m}^{2}$ dredged, corresponding to an increase to about 14 times $(1361 \%)$ the average dry weight material in the water column before dredging (108g dry wt $\mathrm{m}^{-2}$; Fig. 4). 

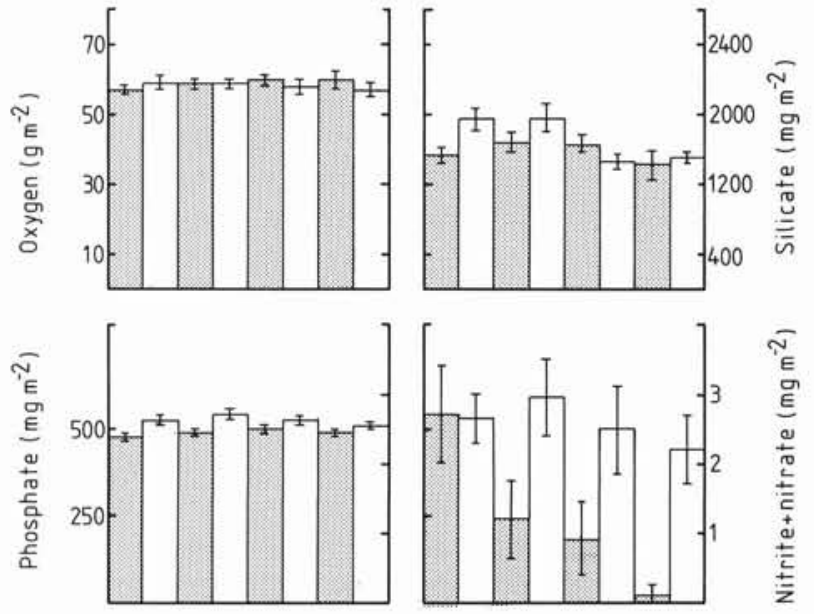

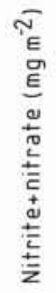
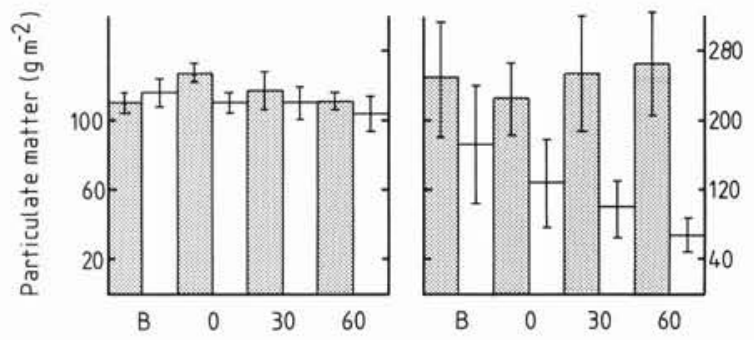

Fig. 5. Depth- and area-integrated values of oxygen, silicate, phosphate, nitrate + nitrite, particulate material, and ammonia at Fur before trawling (eel trawl) and 0 (immediately after trawling), 30, and $60 \mathrm{~min}$ after trawling in the sampling area (shaded columns) and in the control area (open columns). Bars represent SD (standard deviation); $\mathrm{n}=9$ vertical profiles

Ammonia increased in the dredged area and decreased in the control area after dredging (Fig. 4). Horizontal variations, particularly at $9 \mathrm{~m}$ depth, were large and average $\mathrm{m}^{2}$ values were not significantly higher after dredging compared with values before dredging. The average ammonia concentrations per $\mathrm{m}^{2}$ were higher in the control area before dredging due to a few high values at 2 and $7.5 \mathrm{~m}$ depths (data not shown).

Oxygen decreased in the dredged area and increased steadily in the control area (Fig. 4). The decrease was most pronounced in the dredged area at $9 \mathrm{~m}$ depth and the mean value per $\mathrm{m}^{2}$ in the dredged area was significantly (t-test, $\mathrm{p}<0.05$ ) lower immediately after dredging compared with the mean value before dredging.

Considering nitrate, phosphate and silicate, only silicate gave an increase after dredging, although it was not significantly different from the values obtained before dredging. Surprisingly high differences were found in the silicate levels in the dredged area and in the control area.
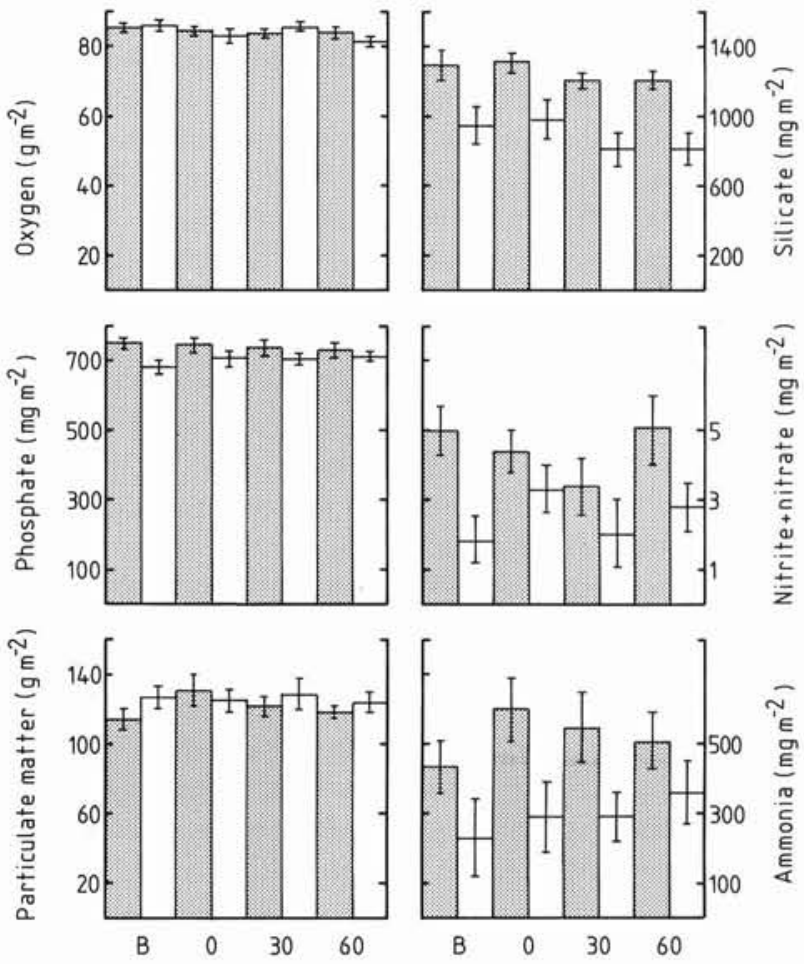

Fig. 6. Depth- and area-integrated values of oxygen, silicate, phosphate, nitrate + nitrite, particulate material, and ammonia at Thisted Broad before trawling (eel trawl) and 0 (immediately after trawling), 30, and $60 \mathrm{~min}$ after trawling in the sampling area (shaded columns) and in the control area (open columns). Bars represent SD (standard deviation); $\mathrm{n}=9$ vertical profiles

\section{Effects of eel trawling}

At Fur Island, the most important changes were observed in the suspended particulate material (Fig. 5), a significant (t-test, $\mathrm{p}<0.01$ ) increase immediately after trawling and a return to the pre-trawl level $60 \mathrm{~min}$ after trawling. Minor (not significant) increases were also found in phosphate, nitrite (data not shown), and silicate, whereas oxygen and nitrate + nitrite did not show clear trends. The large uncertainties in the nitrate + nitrite values were probably because the measured concentrations were close to the detection limit.

At Thisted Broad, a similar significant (t-test, p $<0.01)$ increase in the suspended particulate material was found immediately after trawling (Fig. 6), followed by a decrease back to the start level. In the control area no significant changes occurred. Ammonia increased significantly (t-test, $\mathrm{p}<0.05$ ) after trawling, but the marked differences before trawling between the fishing and control areas complicate interpretation of events. Silicate increased slightly after trawling, whereas no clear tendencies were observed in nitrate + nitrite, phosphate, and oxygen. 
Changes in suspended particulate material recalculated to give values per $\mathrm{m}^{2}$ fished are presented in Fig. 7 . As shown above, dredging caused an immediate increase to about 14 times the material in the water column before dredging (Figs. 4 \& 7). Similar calculations for trawling at Fur and Thisted gave 1067 and $1133 \mathrm{~g} \mathrm{~m}^{-2}$ trawled, corresponding to 960 and $1000 \%$ compared with the material in the water columns before trawling.

\section{Effects of wind}

Measurements of transparency, suspended particulate material, nitrogen, and phosphorus were carried out at 2 locations in the Limfjord during low $\left(3 \mathrm{~m} \mathrm{~s}^{-1}\right)$ and high (15 $\mathrm{m} \mathrm{s}^{-1}$ ) wind velocities (Table 2). Transparency was markedly reduced in windier conditions. Moreover, concentrations of suspended particulate material, inorganic and total nitrogen and phosphorus increased (except nitrate from Kås Broad), with the most pronounced increases for suspended particulate material and total phosphorus.

\section{DISCUSSION}

So far, transport of particles into the water column induced by fishing activities has mainly been documented by photographs (Caddy 1973), or videofilms (Krost unpubl.), and quantitative information appears to be lacking concerning either particles or nutrients. The results here from the 3 locations support the idea that suspended particulate material is resuspended from the bottom into the water column. Similar clouds of suspended particulate material have previously been reported, although they have most often been related to consequences for fish capture (Main \& Sangster 1981), mussel banks (Caddy 1973, Dare 1974), lobsters (Ganz 1980), and benthos (De Groot 1984).

The experimental design allowed an evaluation only of short-term changes since currents moved the water rapidly out of the sampling area. This means that the

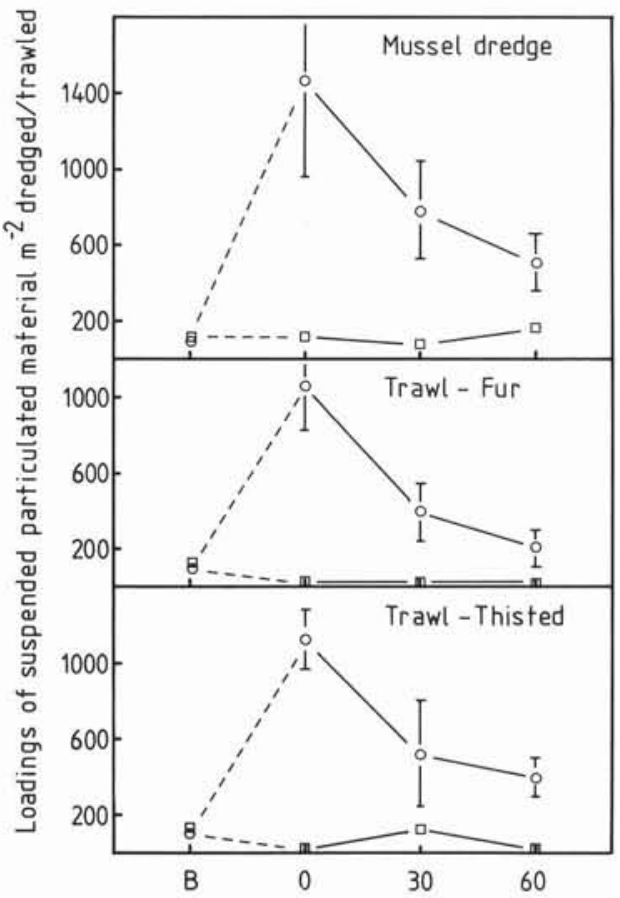

Fig. 7. Effects of fishing (mussel dredge and trawling) per $\mathrm{m}^{2}$ fished on suspended particulate material in the water column. The amount of particles before fishing is the average value for the 9 vertical profiles. The amount of particles after fishing was calculated from the difference before and after fishing at each sampling station. The average value for the 9 stations was then divided by the fished area $\left(1850 \mathrm{~m}^{2}\right.$ for dredging and $2400 \mathrm{~m}^{2}$ for trawling) and multiplied by the sampling area $\left(160000 \mathrm{~m}^{2}\right)$. Bars indicate $95 \%$ confidence limits; $\mathrm{n}=9$ vertical profiles. () Sampling areas; (ㅁ) control areas

results represent a minimum estimate of the effects of the dredging and trawling since some of the suspended particulate material and nutrients probably were carried away before sampling took place. As an alternative to our sampling design, a water mass contaminated from the fishing activities could be followed by means of drifting buoys: however, this would make it difficult to detect the contamination because of rapid dilution by uncontaminated water masses.

Table 2. Particulate matter, transparency and nitrogen and phosphorus compounds from Kås Broad (depth 6.0 to $6.2 \mathrm{~m}$ ) and from Venø Bugt (depth 6.2 to $6.3 \mathrm{~m})$ during high $\left(15 \mathrm{~m} \mathrm{~s}^{-1}\right)$ and low $\left(3 \mathrm{~m} \mathrm{~s}^{-1}\right)$ wind velocities

\begin{tabular}{|c|c|c|c|c|}
\hline & \multicolumn{2}{|c|}{ Kås Broad } & \multicolumn{2}{|c|}{ Venø Bugt } \\
\hline & $3 \mathrm{~m} \mathrm{~s}^{-1}$ & $15 \mathrm{~m} \mathrm{~s}^{-1}$ & $3 \mathrm{~m} \mathrm{~s}^{-1}$ & $15 \mathrm{~m} \mathrm{~s}^{-1}$ \\
\hline Particulate matter $\left(\mathrm{mg} \mathrm{l}^{-1}\right)$ & 13 & 80 & 12 & 84 \\
\hline Transparency (m) & 1.5 & 0.50 & 1.8 & 0.50 \\
\hline Ammonia $\left(\mu \mathrm{g} \mathrm{l}^{-1}\right)$ & 47 & 65 & 120 & 140 \\
\hline Nitrate + nitrite $\left(\mu \mathrm{g} 1^{-1}\right)$ & 650 & 630 & 520 & 560 \\
\hline Total nitrogen $\left(\mu \mathrm{g}^{-1}\right)$ & 1200 & 1300 & 1100 & 1100 \\
\hline
\end{tabular}


In contrast to particles, which sooner or later sink to the bottom again, inorganic nutrients released from the sediment will possibly enter the food web in the water column. Marked changes in ammonia were observed at Livø after dredging and at Fur after trawling. Unfortunately, large spatial differences in the ammonia content were found, and the observed changes were not significantly higher after dredging at Livø. Nevertheless, assuming that the average increase immediately after dredging at Livø in fact was caused by the dredge, the effects corresponded to an increase of $2941 \mathrm{mg}$ ammonia per trawled $\mathrm{m}^{2}$, or 118 times the ammonia content before dredging. Similar calculations from Fur and Thisted Broad were not carried out for the trawling area as a whole, either because the increases in ammonia were only observed just above the bottom in the water column (Fur) or because the ammonia content in the control area was markedly different from the content in the trawling area before trawling (Figs. $5 \& 6$ ). Considering that the concentration of inorganic nitrogen was below $1 \mu \mathrm{M}$ at Livø, it is probable that inorganic nitrogen controlled phytoplankton primary production, and increased internal nitrogen transport induced by dredging would increase phytoplankton primary production.

At Livø the oxygen level decreased significantly after dredging probably because of mixing of reduced products such as methane and hydrogen sulphide and/or because the resuspended particulate material had bacteria attached, exerting an increased oxygen demand in the water column. Whether the observed reduction was caused by chemical or biological oxygen consumption is not clear. Hargrave (1972) demonstrated that chemical oxygen consumption in limnic sediments could constitute more than half the total oxygen consumption. Labile organic compounds can be resuspended from the sediment, and cause immediate changes in the oxygen content. No significant changes in the oxygen content were found using the eel trawl at Fur and Thisted Broad. The relatively low temperature (16 to $17^{\circ} \mathrm{C}$ ) probably prevented a more pronounced effect of the trawling. Higher temperatures, which often occur in the Limfjord during summer, induce increased oxygen consumption and this may accelerate oxygen depletion. If dredging and trawling increase oxygen consumption and extend the periods with oxygen depletion, dredging affects mussels in 2 ways: by removing the mussels and by extending periods of oxygen depletion. In fact, periods of oxygen depletion are thought to regulate production of blue mussels in the Limfjord (Jørgensen 1980).

The effects induced by the mussel dredge and the eel trawls were probably much less than those induced by normal fishing vessels. Individual towing periods are only few minutes for mussel dredging, but several towing periods are made on the same location and over the day dredging is carried out for hours. Eel trawling is normally carried out over several hours. Our towing period was restricted to about $15 \mathrm{~min}$ for both dredging and trawling. On an area basis, dredging was carried out on $1850 \mathrm{~m}^{2}$ and trawling on $2400 \mathrm{~m}^{2}$ compared with an estimated annual trawled/dredged area of $3000 \mathrm{~km}^{2}$ (Nielsen 1985).

An important question is the extent to which dredging and trawling contribute to increased loadings of particles and nutrients compared with natural resuspension. During periods with wind velocities exceeding $15 \mathrm{~m} \mathrm{~s}^{-1}$, resuspension of particles and nutrients occurred in the Limfjord area at depths $<6 \mathrm{~m}$ (Table 2). During summer, however, the wind speed is generally lower. The mean wind velocity during the period May to October 1989 ranged from 5 to $7 \mathrm{~m} \mathrm{~s}^{-1}$ (Fig. 8) and the frequency of wind velocities exceeding about $11 \mathrm{~m} \mathrm{~s}^{-1}$ was below $15 \%$ during May to October. Wind velocities reaching more than $18 \mathrm{~m} \mathrm{~s}^{-1}$, however, did occur during May to October (Fig. 8), suggesting occasional wind-induced
Fig. 8. (A) Seasonal changes of various groups of wind velocities $\left(\mathrm{m} \mathrm{s}^{-1}\right)$ during 1989; (B) actual monthly mean wind velocity (columns) and normal (mean for period 1931 to 1960) monthly mean values. Actual maximum wind velocities are indicated on the top of each column

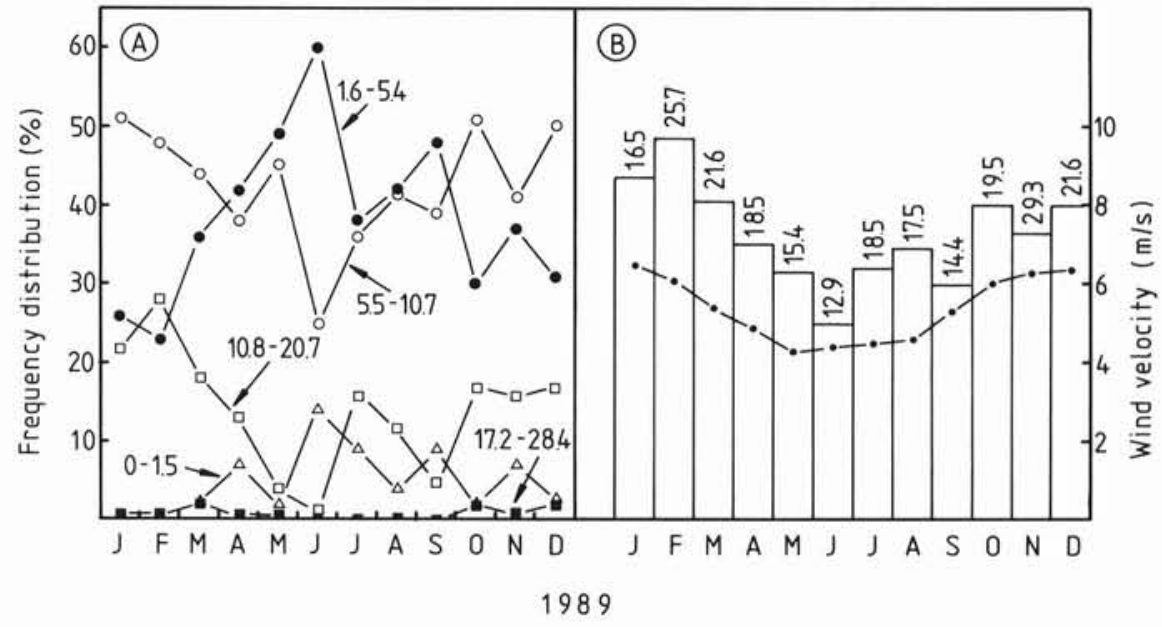

1989 
turbulences similar to those presented in Table 2. Marked decreases were found in transparency during high wind velocities $\left(15 \mathrm{~m} \mathrm{~s}^{-1}\right)$ and suspended particulate matter, total phosphorus and inorganic nutrients increased. Assuming no vertical differences in the distribution of suspended particulate matter, the observed changes between 3 and $15 \mathrm{~m} \mathrm{~s}^{-1}$ corresponded to an increase of 402 to $432 \mathrm{~g}$ dry wt $\mathrm{m}^{-2}$. In comparison, the 15 min dredging at Livø (depth $9 \mathrm{~m}$ ) gave an increase of $1470 \mathrm{~g}$ dry wt $\mathrm{m}^{-2}$ dredged, roughly 3 times more. During summer, when nutrients are generally low in the Limfjord, an effective mixing of sediment material will have important consequences for the nutrient regime. Mussel dredging occurs throughout the year except during July, whereas most of the trawling for eels takes place during summer. It is therefore likely that dredging and trawling during summer periods dominated by wind velocities from 5 to $7 \mathrm{~m} \mathrm{~s}^{-1}$ will deteriorate the water quality by increasing oxygen consumption and phytoplankton primary production. A complete evaluation of the demarcation of trawling and dredging effects versus wind-induced effects is not possible from the present material and needs more attention. Particular emphasis should be placed on estimating the magnitude of trawling and examining the effects of wind-stress on the nutrient regime and oxygen balance in the Limfjord. Although the results from the wind experiments can be compared to those from the fishing experiments with respect to suspended particulate matter, seasonal changes in the nutrient concentrations in the sediments prevent a close comparison of the nutrient data from the 2 sets of observations.

In conclusion, the dredging and trawling employed here increased particulate material almost immediately to $1361 \%$ and 960 to $1000 \%$, respectively, compared with the standing stock of particles. Oxygen consumption also increased, and the observed increases in nutrients (particularly ammonia and silicate) were a further apparent effect of the fishing activities. The consequences of dredging and trawling include increased oxygen consumption, nutrient concentration, and possible phytoplankton primary production. The importance of these changes compared to wind-induced transport of particles and nutrients needs further examination.

Acknowledgements. We thank Dr Peter Krost and Kirsten Christoffersen for valuable comments on the manuscript, the crew of the ships Limgrim and Harfisken, and Jens Anton Christensen, Bent Jensen and Per Sand Kristensen for valuable help during sampling, the Limfjord Committee for permission to use the presented data, Viborg Amtskommune for permission to present data from Venø Bugt and Kås Bredning, and The Danish Meteorological Institute for permission to present data for wind velocities. This study was supported by grants from the Limfjord Committee, Danish Institute for Fisheries and Marine Research. A grant to Bo Riemann from Director, dr, techn. A. N. Neergaards og Hustrus Fond made the writing of this article possible.

\section{LITERATURE CITED}

Caddy, J. F. (1973). Underwater observations on tracks of dredges and trawls and some effects of dredging on a scallop ground. J. Fish. Res. Bd Can. 30: 173-180

Crosby, N. T. (1967). The determination of nitrite in water using Cleve's acid, 1-naphthylamin-7-sulphonic acid. Proc. Soc. Wat. Treatm. Exam. 16: 51

Dare, P. J. (1974). Damage caused to mussels (Mytilus edulis L.) by dredging and mechanized sorting. J. Conseil 35: 296-299

De Groot, S. J. (1984). The impact of bottom trawling on the benthos fauna of the North Sea. Ocean Mgmt 9: 177-190

Ganz, A. (1980). Otter trawl induced lobster damage evaluation. Compl. Rep. R.I. Dept. Environm. Manage., RIDEMProj. 3-279-R/3-310-R, p. 1-28

Graham, M. (1955). Effect of trawling on animals in the sea bed. Deep Sea Res. 3: suppl., 1-6

Hargrave, B. T. (1972). Aerobic decomposition of sediment and detritus as a function of particle surface area and organic content. Limnol. Oceanogr. 17: 583-596

ICES (1988). Report of the study group on the effects of bottom trawling. Comm. Meet. int. Coun. Explor. Sea C.M.-ICES B: 56

Jackson.M. L. (1958). Soil chemical analysis. Prentice-Hall, Inc., Englewood Cliffs

Jørgensen, B. B. (1980). Seasonal oxygen depletion in the bottom waters of a Danish fjord and its effect on the benthic community. Oikos 34: 68-76

Koroleff, F. (1968). Determination of total phosphorus in natural waters by means of persulphate oxidation. Int. Coun. Explor. Sea (ICES), rep. 3

Main, J., Sangster, G. I. (1981). A study of sand clouds produced by trawl boards and their possible effect of fish capture. Scott. Fish. Res. Rep. 20: 1-20

Mullin, J. B., Riley, J. B. (1966). The calorimetric determination of silicate with special reference to sea natural waters. Analyt. Chem. Acta 12: 162-176

Murphy, I., Riley, T. P. (1962). A modified single solution method for the determination of phosphate in natural waters. Analyt. Chim. Acta. 27: 21-26

Nielsen, L. P. (1985). Trawlfiskeri i Limfjorden. Intern rapport til Limfjordkomiteen, p. 1-10 (in Danish)

Rauck, G. (1985). Wie schädlich ist die Seezungenbaumkurre für Bodentiere? Infn. Fischw. 32: 165-168

Redant, F. (1987). A bibliography on the effects of bottom fishing gear and harvesting techniques on benthic biota, Working document to the ICES Benthos Ecology Working Group, Edinburgh, April 1987

Riemann, B., Schierup, H.-H. (1978). Effects of storage and conservation on the determination of ammonia in water samples from four lake types and a sewage plant. Wat. Res. 12: 849-853

Solórzano, L. (1969). Determination of ammonia in natural waters by the phenolhypochlorite method. Limnol. Oceanogr. 14: 799-801

Manuscript first received: April 11, 1990

Revised version accepted: September 18, 1990 